\title{
In Memoriam: Robert H. Rasche
}

Bob Rasche was a champion of the St. Louis Fed. He devoted his energy and imagination to cultivating an environment of public service and rigorous economic research. Bob died June 2, 2016. He is survived by his wife of 52 years, Dorothy Anita Bensen; his children, Jeanette [Bart] Little and Karl [Tuhina] Rasche; and his brother, Richard A. [Jamie] Rasche.

Bob was born in New Haven, Connecticut. He received his $\mathrm{BA}$ in economics and mathematics from Yale University and his $\mathrm{PhD}$ in economics from the University of Michigan. Bob had a distinguished career in academia. He published many research papers in top scholarly journals and was well respected by his peers in the economics profession. The IDEAS/RePEc bibliographic database provides some details: Bob's publishing rank is in the top 3\% of economists. His most cited paper comes from the St. Louis Fed Review, "Market Anticipations of Monetary Policy Actions," with co-authors

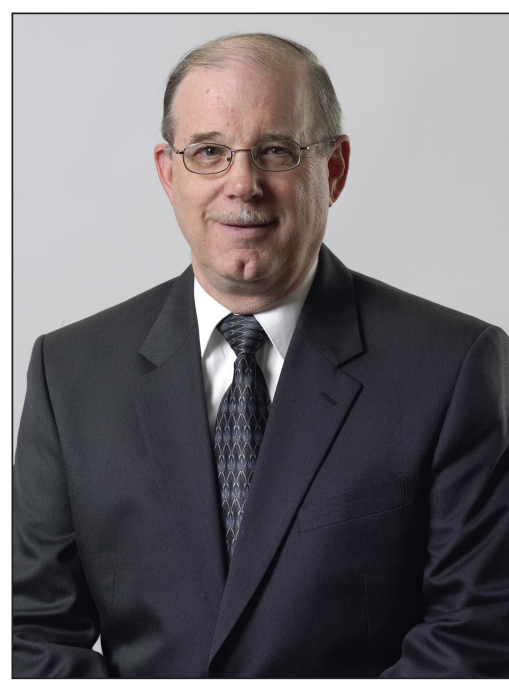

Robert Harold Rasche 1941-2016

Former Director of Research Federal Reserve Bank of St. Louis

William Poole and Daniel Thornton. And his most downloaded paper comes from the Carnegie-Rochester Conference Series on Public Policy: "Energy Price Shocks, Aggregate Supply and Monetary Policy: The Theory and the International Evidence."

In January 1999, Bob became the St. Louis Fed's director of research under Bank president William Poole. Bob was already well connected to the St. Louis Fed before he accepted the role: In August 1971, Bob took a leave of absence from the University of Pennsylvania and worked as a visiting scholar at the St. Louis Fed. In August 1976, Bob took a leave of absence from Michigan State University and returned to the St. Louis Fed, again, as a visiting scholar. Bob paid close attention to the research being conducted there and was an avid reader and user of the Bank's research publications and data services.

His work within the Federal Reserve and the context of central banking in general prepared him well for his tenure at the St. Louis Fed. He was an MIT research associate on the Federal Reserve Board-MIT Monetary Research Project; a visiting scholar at the San Francisco Fed; a visiting scholar at the Bank of Japan's Institute for Monetary and Economic Studies; and a prolific author of Shadow Open Market Committee position papers. Bob amassed a decades-deep understanding of the research environment and the overall mission of the Federal Reserve. 
At the St. Louis Fed, Bob established objectives for conducting high-quality economic research, disseminating that research in scholarly journals and Bank publications, and bolstering the reach and influence of the Bank throughout the Federal Reserve System and academia.

Bob was also one of the most vocal and persistent advocates of delivering accurate data and information to the public. He had closely followed the St. Louis Fed's historical trajectory of collecting, analyzing, and sharing economic data. He understood and respected that tradition and viewed it as a vital public service. One of his legacies is that he expanded and enhanced FRED, the Bank's prime data service, at a key moment in its history: He made a compelling case to the Bank's president and its senior leaders that the St. Louis Fed's mission of public service should continue and thrive. And it did thrive. During Bob's tenure, the data and information services grew in size, scope, and recognition.

Many of the current projects in the St. Louis Fed's Research Division began with Bob Rasche, and existing lines of business were expanded and strengthened. Bob led and inspired his staff by his own example, with authentic passion and engagement both inside and outside the Bank:

Bob was a family archivist, compiling information on his own family history, which he organized into a multigenerational collection after he retired. He also envisioned and nurtured a realm of St. Louis Fed data services, including a database of historical "vintage" economic data (ALFRED) and a digital research archive of Federal Reserve and national economic history (FRASER).

Bob and his wife, Dottie, had many opportunities for domestic and international travel, including a number of cruises to Norway, the Baltic, and Alaska. With that expansive vision, he conceived of and brought about GeoFRED, an innovative extension of the FRED database that provides geographic maps of data.

As a teenager, Bob delivered the New Haven Register for six years. His work ethic and vigor persisted: He would arrive at the office early in the morning, passionately describing the ideas that had occurred to him overnight, and a new project was born. He also produced economic research his entire career. Current St. Louis Fed president, James Bullard, remarked on the occasion of Bob's retirement that Bob had published five academic papers in one year alone.

Bob was also an avid carpenter. He was curious, creative, and precise in his expectations and measurements of success, and he expected the finished products to be polished and true. Bob crafted valuable and lasting service to the public, the economics profession, and the Federal Reserve System. His contributions stand out and inspire those who continue this work. 